\title{
Pengaruh Teknik Pembelajaran Kreatif Produktif terhadap Hasil Belajar IPS Terpadu Siswa SMP
}

\author{
Husnul Khatimah \\ Program Studi Pendidikan Sejarah, STKIP Yapis Dompu \\ E-mail: khatimahhusnul@gmail.com
}

Article History: Received: 2022-01-11 || Revised: 2022-02-01 || Published: 2022-02-15

Sejarah Artikel : Diterima: 2022-01-11 || Direvisi: 2022-02-01 || Dipublikasi: 2022-02-15

\begin{abstract}
The aim of this study is that teachers can use a variety of learning methods so that students are interested in being active in learning, so that an effective learning atmosphere will be created and learning objectives can be achieved optimally. In improving the teaching process, the teacher's role is very important, as the manager of student activities, the teacher is also expected to guide and assist students so that during the learning process all children's activities can be controlled. The type of this research is quantitative research. The population of the study was students of class VIII which consisted of eight classes, namely grades VIII A to VIII G totaling 218 students, while the sample in the study consisted of some students of class VIII (only some students). The results obtained that the use of methods that are interesting to students needs to be given so that students are more involved and involved in the learning process as well as improve learning achievement, so researchers can conduct experiments on one of the learning techniques, namely Creative-Productive.
\end{abstract}

Keywords: Effective, Learning, Learning Achievement, Creative-Productive.

\begin{abstract}
Abstrak
Tujuan penelitian ini adalah guru dapat menggunakan metode pembelajaran yang bervariasi agar siswa tertarik untuk aktif dalam pembelajaran, sehingga akan tercipta suasana belajar yang efektif dan tujuan belajar dapat tercapai secara optimal. Dalam perbaikan proses pengajaran ini peranan guru sangat penting, selaku pengelola kegiatan siswa, guru juga diharapkan membimbing dan membantu siswa agar selama proses pembelajaran semua kegiatan anak dapat dikontrol. Adapun jenis penelitian ini adalah penelitian kuantitatif. Populasi penelitian yaitu siswa kelas VIII yang terdiri atas delapan kelas yaitu kelas VIII A sampai dengan VIII G berjumlah 218 orang siswa, sementara sampel dalam penelitian adalah sebagian siswa kelas VIII (hanya sebagian siswa). Hasil yang diperoleh bahwa penggunaan metode yang menarik terhadap siswa perlu diberikan sehingga siswa lebih berperan dan terlibat dalam proses pembelajaran sehingga dapat meningkatkan prestasi belajar, maka peneliti dapat melakukan eksperimen tentang salah satu teknik pembelajaran yaitu Kreatif-Produktif.
\end{abstract}

Kata kunci: Pembelajaran, Efektif, Prestasi Belajar, Kreatif-Produktif.

\section{PENDAHULUAN}

Visi pendidikan Indonesia yang ditetapkan Kementrian Pendidikan Nasional (2012) yaitu terselenggaranya layanan prima pendidikan dan kebudayaan nasiona untuk membentuk insan Indonesia yang cerdas dan berkarakter kuat, merupakan gambaran dan cerminan kondisi masa depan Indonesia yang akan dicapai dan diarahkan secara konsisten, antisipatif, inovatif, serta produktif. Visi tersebut telah menjadi rumusan dan dituangkan pada Undang-Undang No 20 Tahun 2003 tentang Sistem Pendidikan Nasional dimana tujuan akhirnya adalah mewujudkan pranata sosial yang kuat dan berwibawa untuk memberdayakan semua warga negara Indonesia berkembang menjadi manusia yang berkualitas sehingga mampu dan proaktif menjawab tantangan zaman yang selalu berubah, tujuan tersebut diamanatkan dalam Peraturan Menteri Pendidikan Nasional No. 41 Tahun 2007 tentang Standar Proses untuk Satuan Pendidikan Dasar dan Menengah disebutkan bahwa pendidikan diselenggarakan sebagai proses pembudayaan dan pemberdayaan siswa yang berlangsung sepanjang hayat. Guru harus memberikan keteladanan, membangun 
kemauan dan mengembangkan potensi dan kreativitas siswa. Proses pembelajaran pada setiap satuan pendidikan dasar harus interaktif, inspiratif, menyenangkan, menantang, memotivasi siswa untuk berpartisipasi aktif, mengembangkan prakarsa, kreativitas, dan kemandirian sesuai dengan bakat, minat dan perkembangan fisik serta psikologis siswa (BSNP 2007: 5-6).

Pada implementasinya guru sebagai orang yang berdiri langsung di depan kelas untuk mencerdaskan siswa memiliki kewajiban untuk menciptakan kegiatan pembelajaran yang menarik dan menyenangkan sehingga indikator kualitas pembelajaran dapat tercapai secara efektif dan efisien. Untuk itu guru memerlukan strategi pembelajaran agar mempermudah proses pembelajaran sehingga dapat mencapai hasil yang optimal. Strategi pembelajaran merupakan pemikiran dan pengupayaan secara strategis dalam memilih, menyusun, memobilisasi dan mensinergikan segala cara, sarana/prasarana, dan sumber daya untuk mencapai tujuan, Strategi pembelajaran memiliki pengertian arti luas dan arti sempit, dalamarti luas merupakan suatu cara atau seperangkat cara atauteknik yang dilakukan dan ditempuh oleh guru atau anak didik dalam melakukan upaya terjadinya suatuperubahan tingkah laku atau sikap. Dalam arti sempit, strategi pembelajaran dapat dimaknai tidak hanya menyangkut perencanaan pembelajaran, tetapi juga termasuk dalam pelaksanaan pembelajaran dan evaluasi pembelajaran sebagai tiga elemen penting dalam tahapan pembelajaran. Secara khusus, strategi biasa dilakukan oleh guru secara tidak tertulis, mengacu pada pengertian startegi pembelajaran tersebut dimana tugas guru berperan besar dalam perencanaan pembelajaran bagi peserta didik, maka guru diharuskan mengembangkan kurikulum di sekolah. Oleh karena itu, guru memerlukan acuan standar isi untuk mengembangkan kurikulum, kurikulum tersebut yang dijabarkan dalam PeraturanMenteri Pendidikan Nasional Nomor 22 tahun 2006 adalah KTSP atau Kurikulum Tingkat Satuan Pendidikan.

Salah satu mata pelajaran yang berfungsi mengembangkan kemampuan dan membentuk watak serta peradaban bangsa adalah mata pelajaran sejarah. Hal ini dikarenakan mata pelajaran sejarah memiliki arti penting dalam pembentukan kesadaran dan wawasan kebangsaan.Arti penting ini dapat ditangkap dari makna edukatif dari pendidikan sejarah itu sendiri.Makna yang bisa ditangkap dari pendidikan sejarah adalah bahwa pendidikan sejarah bisa memberikan kearifan dan kebijaksanaan bagiyang mempelajarinya, pembelajaran sejarah sekarang ini menuntut siswa untuk dapat aktif dalam proses pembelajaran, memahami maknamateripelajaran yang dipelajarinya dengan mengkaitkan materi tersebut dengan konteks kehidupan mereka sehari-hari sehingga pengetahuan yang dimiliki siswa sewaktu dibangku sekolah dapat diterapkan dalam kehidupan sehari-hari. Selain itu, pembelajaran sekarang ini menempatkan siswa sebagai subjek belajar. Dengan kata lain, pembelajaran ditekankan atau berorientasi pada aktivitas siswa. Dalam pengajaran sejarah, metode dan pendekatan serta model yang dipilih, merupakan alat komunikasi yang baik antara pengajar dan peserta didik, sehingga setiap pengajaran dan uraian sejarah yang disajikan dapat memberikan motivasi belajar.

Selama ini pembelajaran sejarah di sekolah kurang begitu diminati oleh siswa. Pelajaran sejarah dianggap sebagai pelajaran yang seolah-olah cenderung "hapalan". Bahkan kebanyakan siswa menganggap bahwa pelajaran sejarah tidak membawa manfaat karena kejadiannya adalah masa lampau. Oleh karena itu, pelajaran IPS hanya dianggap sebagai pelajaran pelengkap, apalagi mata pelajaran IPS tidak di-UN-kan. Ditambah lagi dengan kebijakan pemerintah yang semakin menyempitkan gerak langkah pembelajaran IPS, yakni dengan semakin kecilnya porsi jam pelajaran IPS di sekolah.Tidak mengherankan jika hasil IPS siswa juga cenderung kurang memuaskan, selama proses mengajar, guru belum optimal dalam mengkondisikan kelas sehingga suasana kelas menjadi gaduh. Dalam menjelaskan materi Sejarah guru belum menggunakan contoh yang konkret. Akibatnya siswa kesulitan dalam memahami materi yang dijelaskan oleh guru. Guru belum menyebarkan kesempatan berpartisipasi dalam memimpin diskusi kelompok kecil sehingga menyebabkan dalam proses diskusi belum semua anggota kelompok aktif dalam diskusi. Pada akhir pembelajaran guru belum memberikan tindak lanjut dan belum menyimpulkan pembelajaran IPS yang telah dilakukan bersama-sama dengan siswa.

Pada aspek aktivitas siswa, siswa masih pasif dalam pembelajaran. Siswa tidak mau bertanya kepada guru apabila belum mengerti.Begitu pula pada saat guru memberikan pertanyaan, beberapa siswa yang menjawab pertanyaan yang diberikan oleh guru dan lebih banyak siswa yang diam mendengarkan saja tanpa memberikan pendapat dan mengemukakan gagasannya. Keberanian 
siswa untuk mengungkapkan pendapat ide dalam pembelajaran, banyak didominasi oleh beberapa siswa dan yang lain tidak berpendapat. Pembelajaran lebih berpusat pada guru, sehingga membatasi kreatifitas siswa dalam proses pembelajaran.

Mengatasi hal tersebut guru harus dapat menggunakan metode pembelajaran yang bervariasi agar siswa tertarik untuk aktif dalam pembelajaran, sehingga akan tercipta suasana belajar yang efektif dan tujuan belajar dapat tercapai secara optimal. Dalam perbaikan proses pengajaran ini peranan guru sangat penting, selaku pengelola kegiatan siswa, guru juga diharapkan membimbing dan membantu siswa agar selama proses pembelajaran semua kegiatan anak dapat dikontrol, strategi kreatif-produktif dikembangkan berdasarkan berbagai pendekatan pembelajaran yang diasumsikan mampu meningktakan kualitas proses belajar mengajar. Strategi pembelajaran kreatif-produktif memiliki beberapa karakteristik yang membedakannya dengan strategi pembelajaran lainnya. Kelebihan strategi pembelajaran kreatif-produktif antara lain sebagai berikut : a) keterlibatan siswa secara intelektual dan emosional dalam pembelajaran; b) siswa didorong untuk menemukan/mengonstruksi sendiri konsep yang sedang dikaji melalui penafsiran yang dilakukan dengan berbagai cara seperti observasi, diskusi atau percobaan; c) siswa diberi kesempatan untuk bertanggung jawab menyelesaikan tugas bersama; d) pada dasarnya untuk menjadi kreatif seseorang harus bekerja keras berdedikasi tinggi, antusias, serta percaya diri. Mengacu pada karakteristik tersebut, strategi pembelajaran kreatif produktif diasumsikan mampu memotivasi siswa dalam melaksanakan berbagai kegiatan sehingga merasa tertantang menyelesaikan tugas-tugasnya secara kreatif (Wena 2011 : 140).

Permasalahan seperti diatas banyak dialami oleh sekolah pada umumnya, begitu juga di SMP Negeri 2 Dompu.SMP ini termasuk SMP yang cukup diminati di Kabupaten Dompu karena mutu pendidikan di SMP ini sudah lumayan baik, akan tetapi berdasarkan berdasarkan studi pendahuluan dan observasi yang telah dilakukan peneliti di SMP ini pada tanggal 23 Oktober 2016, proses pembelajaran IPS di SMP ini cenderung kurang bervariatif karena dalam mengajar guru sangat sering menggunakan metode konvensional yaitu metode ceramah, sehingga guru belum dapat mendekatkan siswa dengan pengalaman belajarnya dan siswa masih kurang dalam hal kemampuan berpikir kritis, kreatif, mengkonstruksi pengetahuannya, serta cenderung pasif. Peran guru didalam kelas masih sangat dominan dan keterlibatan siswa dalam proses pembelajaran sangat terbatas, sehingga pembelajaran masih bersifat satu arah. Hal ini berdampak pada hasil belajar sejarah siswa yang kurang memuaskan, kemudian observasi kedua pada tanggal 20 maret 2017, dalam proses pembelajaran siswa lebih banyak keluar masuk keluar masuk, ribut dan kurang antusias dalam mengikuti pembelajaran karena guru lebih banyak menyampaikan materi dengan metode satu arah, meskipun kadang bergantian dengan metode lain seperti tanya jawab, diskusi dan demonstrasi. Namun akibatnya tidak terlalu berefek pada tingkat kemauan dan prestasi siswa.

Ini juga di dukung oleh hasil wawancara yang dilakukan peneliti dengan guru mata pelajaran IPS yaitu ibu Miskul Khitam, S. Pd mengatakan bahwa dalam proses pembelajaran guru menggunakan beberapa metode seperti ceramah, diskusi, tanya jawab dan demonstrasi. Adapun tujuanmenggunakan metode yang bervariasi adalah untuk mencapai tujuan pembelajaran dan materi bisa dimengerti dan mudah di serap. Namun dalam prakteknya penggunaan ceramah yang lebih dominan mengakibatkan siswa kurang bersemangat. Terkadang guru menggunakan metode lainnya di atas namun kurang efektif karena siswa terkadang bosan dan ribut di dalam kelas, keberhasilan suatu proses pembelajaran dapat diukur dari keberhasilan siswa mengikuti pembelajaran tersebut. Sedangkan hasil belajar yang baik harus didukung oleh pembelajaran yang berkualitas yakni pembelajaran yang mampu melibatkan keaktifan dan daya kreatifitas siswa. Oleh sebab itu, perlu dipilih suatu pembelajaran yang mampu melibatkan keaktifan dan daya kreativitas siswa.

Menyikapi hal tersebut di atas, maka peneliti bermaksud mengadakan penelitian dengan judul "Pengaruh Teknik Pembelajaran Kreatif Produktif Terhadap Hasil Belajar IPS Terpadu Siswa Kelas VIII SMP Negeri 2 Dompu". Dengan diterapkannya pembelajaran Kreatif dan Produktif, maka diharapkan dapat berpengaruh terhadap hasil belajar dalam pembelajaran IPS terpadu.

\section{METODE PENELITIAN}

Pendekatan yang digunakan dalam penelitian ini adalah pendekatan kuantitatif, yang menurut Sugiyono(2011:32) metode kuantitatif adalah pendekatan ilmiah yang memandang suatu realitas 
itu dapat diklasifikation,konkrit,teramati danterukur,hubungan variabelnyabersifat sebab akibat dimana data penelitiannya berupa angka-angka dan analisisnya menggunakan statistik. Populasi merupakan keseluruhan subyek penelitian. Dalam penelitian ini peneliti menggunakan seluruh siswa kelas VIII SMP Negeri 2 Dompu. adapun populasi penelitian Siswa kelas VIII terdiri atas delapan kelas yaitu kelas VIII A sampai dengan VIII G berjumlah 218 orang siswa Meskipun terdiri atas beberapa kelas yang berbeda, seluruh kelas sebagai kelas populasi tersebut merupakan satu kesatuan, karena keseluruhannya mempunyai kesamaan, yaitu siswa-siswi tersebut berada dalam tingkat yang sama, yaitu kelas VIII SMP. Sampel adalah sebagian atau wakil populasi yang diteliti. Sampel pada penelitian ini menggunakan sebagian siswa kelas VIII, tetapi hanya menggunakan sebagian siswa saja. Dalam hal ini sampel yang digunakan harus representative (mewakili populasi), sehingga harus dilakukan. Teknik pengumpulan tidak diabaikan begitu saja, diantaranya Metode Tes dan Angket.

Teknik Analisis Data sudah jelas, digunakan untuk menjawab rumusan masalah dan Hipotesis merupakan jawaban sementara terhadap rumusan masalah atau sub masalah yang diajukan oleh peneliti karena sifatnya sementara maka perlu dibuktikan kebenarannya melalui data empirik yang terkumpul atau penelitian ilmiah (Riduwan, 2009: 29). Di dalam menentukan penerimaan dan penolakan hipotesis maka hipotesis alternatif (Ha) diubah menjadi hipotesis nol (Ho), melalui analisis Regresi Linier sederhana, yang merupakan metode statistic yang berfungsi untuk menguji hubungan sebab akibat antara variabel bebas $(\mathrm{X})$ dengan variabel terikat $(\mathrm{Y})$ dengan persamaan berikut:

$$
\begin{aligned}
& \mathrm{Y}=\mathrm{a}+\mathrm{bX} \\
& \text { Keterangan: } \\
& \mathrm{a}=\text { Parameter Konstanta } \\
& \mathrm{b}=\text { Koefisien Arah Regresi } \\
& \mathrm{Y}=\text { Variabel Dependent } \\
& \mathrm{X}=\text { Variabel Independent } \\
& \mathrm{n}=\text { Jumlah Pasangan Data (Sampel) (Arikunto, 2010: 188). }
\end{aligned}
$$

Untuk menghitung nilai a (konstanta) digunakan rumua sebagai berikut:

$\mathrm{a}=\left(\sum \mathrm{y}\right)\left(\sum \mathrm{x} 2\right)-\left(\sum \mathrm{x}\right)\left(\sum \mathrm{xy}\right)$

$\mathrm{n}\left(\sum \mathrm{x} 2\right)-\left(\sum \mathrm{x}\right) 2$

untuk menghitunh nilai b (nilai koofisien) digunakan rumus sebagai berikut:

$$
\begin{aligned}
\mathrm{b}= & \mathrm{n}\left(\sum \mathrm{xy}\right)-\left(\sum \mathrm{x}\right)\left(\sum \mathrm{y}\right) \\
& \mathrm{n}\left(\sum \mathrm{x} 2\right)-\left(\sum \mathrm{x}\right) 2 \quad \text { (Arikunto, 2010: 190). }
\end{aligned}
$$

\section{HASIL DAN PEMBAHASAN}

\section{A. Hasil Penelitian}

Penelitian ini melibatkan dua variabel yakni pembelajaran strategi kreatifproduktif sebagai variabel bebas dan hasil belajar siswa sebagai variabel terikat, data diperoleh dari 35 orang siswa kelas VIII SMP Negeri 2 Dompu, untuk mengetahui hasil penelitian ini, maka data yang telah dihimpun selanjutnya akan dianalisis dengan menggunakan rumus regresi linier sederhana:

Tabel 1. Tabel distribusi Data Variabel $X$ dan $Y$

\begin{tabular}{cccccccccccc}
\hline NO & $\mathbf{X}$ & $\mathbf{Y}$ & $\mathbf{X}^{\mathbf{2}}$ & $\mathbf{Y}^{\mathbf{2}}$ & $\mathbf{X Y}$ & $\mathbf{N O}$ & $\mathbf{X}$ & $\mathbf{Y}$ & $\mathbf{X}^{\mathbf{2}}$ & $\mathbf{Y}^{\mathbf{2}}$ & $\mathbf{X Y}$ \\
\hline 1 & 72 & 80 & 5184 & 6400 & 5760 & 19 & 67 & 65 & 4489 & 4225 & 4355 \\
\hline 2 & 73 & 25 & 5329 & 625 & 1825 & 20 & 72 & 75 & 5184 & 5625 & 5400 \\
\hline 3 & 72 & 50 & 5184 & 2500 & 3600 & 21 & 73 & 55 & 5329 & 3025 & 4015 \\
\hline 4 & 71 & 25 & 5041 & 625 & 1775 & 22 & 64 & 90 & 4096 & 8100 & 5760 \\
\hline 5 & 67 & 100 & 4489 & 10000 & 6700 & 23 & 69 & 90 & 4761 & 8100 & 6210 \\
\hline 6 & 65 & 95 & 4225 & 9025 & 6175 & 24 & 67 & 90 & 4489 & 8100 & 6030 \\
\hline 7 & 69 & 50 & 4761 & 2500 & 3450 & 25 & 73 & 50 & 5329 & 2500 & 3650 \\
\hline 8 & 73 & 100 & 5329 & 10000 & 7300 & 26 & 63 & 80 & 3969 & 6400 & 5040 \\
\hline 9 & 63 & 25 & 3969 & 625 & 1575 & 27 & 65 & 65 & 4225 & 4225 & 4225 \\
\hline 10 & 66 & 100 & 4356 & 10000 & 6600 & 28 & 69 & 80 & 4761 & 6400 & 5520 \\
\hline 11 & 70 & 100 & 4900 & 10000 & 7000 & 29 & 66 & 85 & 4356 & 7225 & 5610 \\
\hline 12 & 72 & 100 & 5184 & 10000 & 7200 & 30 & 65 & 25 & 4225 & 625 & 1625 \\
\hline 13 & 74 & 70 & 5476 & 4900 & 5180 & 31 & 69 & 75 & 4761 & 5625 & 5175 \\
\hline 14 & 69 & 75 & 4761 & 5625 & 5175 & 32 & 63 & 70 & 3969 & 4900 & 4410 \\
\hline
\end{tabular}




\begin{tabular}{ccccccccccccc}
\hline 15 & 67 & 30 & 4489 & 900 & 2010 & 33 & 66 & 95 & 4356 & 9025 & 6270 \\
\hline 16 & 68 & 95 & 4624 & 9025 & 6460 & 34 & 69 & 80 & 4761 & 6400 \\
\hline 17 & 71 & 50 & 5041 & 2500 & 3550 & 35 & 73 & 100 & 5329 & 10000 & 7300 \\
\hline 18 & 73 & 60 & 5329 & 3600 & 4380 & $\Sigma N$ & $\mathbf{2 4 0 8}$ & $\mathbf{2 5 0 0}$ & $\mathbf{1 6 6 0 6 0}$ & $\mathbf{1 9 9 3 5 0}$ & $\mathbf{1 7 1 8 3 0}$ \\
\hline
\end{tabular}

Data pada tabulasi diatas merupakan data hasil distribusi dari kedua variabel penelitian. Pendistribusian data penelitian tersebut dimaksudkan untuk mempermudah proses analisis data, dari tabel kerja diatas diperoleh nilai nilai sebagai berikut:

$$
\begin{array}{ll}
\mathrm{N} & : 35 \\
\sum \mathrm{X}: 2408 \\
\sum \mathrm{Y}: 2500 \\
\sum \mathrm{X}^{2}: 16606 \\
\sum \mathrm{Y}^{2}: 199350 \\
\sum \mathrm{XY}: 171830
\end{array}
$$

\section{B. Pembahasan}

Model-model Pembelajaran adalah beberapa cara atau teknik yang digunakan oleh guru kepada siswa dalam menyajikan materi pembelajaran dalam sebuah proses pembelajaran agar tujuan pembelajaran yang sudah dirancang dapat tercapai. Beberapa model pembelajaran ini diterapkan guru saat mengajarkan sesuatu kepada siswa dengan tujuan agar pesan dari materi pembelajaran itu sendiri tersampaikan dengan mudah. Model pembelajaran yang sudah ada sejauh ini yang diberikan guru hanya didominasi oleh metode konvesional saja, sehingga siswa merasa tidak dilibatkan karena hanya guru yang berperan penting dalam proses pembelajaran tersebut, proses pembelajaran akan berlangsung baik apabila terdapat interaksi antara guru dan siswa. Dalam proses pembelajaran tidak semua siswa mampu berkonsentrasi dalam waktu yang relatif lama. Daya serapsiswa terhadap bahan yang diberikan juga bermacam-macam, ada yang cepat, ada yang sedang dan ada yang lambat. Faktor intelegensi mempengaruhi daya serap siswa terhadap bahan pelajaran yang diberikan oleh guru. Perbedaan daya serap siswa tersebut, memerlukan modelmodel pembelajaran yang tepat yang harus diberikan kepada siswa dalam kelas.

Salah satu cara adalah menggunakan metode yang menarik sehingga siswa lebih berperan dan terlibat dalam proses pembelajaran, maka peneliti bermaksud untuk melakukan eksperimen tentang salah satu teknik pembelajaran yaitu Creatif-Produktif.

\section{SIMPULAN DAN SARAN}

\section{A. Simpulan}

Berdasarkan uraian yang terdapat pada hasil analisis data pada bab IV, maka dapat disimpulkan bahwa hasil penelitian ini menunjukkan, bahwa tidak ada pengaruh yang signifikan dari teknik kreatif-Produktif terhadap hasil belajar pada mata pelajaran IPS di kelas VIII SMP Negeri 2 Dompu.

\section{B. Saran}

Adapun saran-saran yang peneliti ingin sampaikan sesuai dengan hasil penelitian ini adalah sebagai berikut:

\section{Bagi guru}

Hasil penelitian ini diharapkan dapat berguna sebagai masukan kepada guru khususnya guru mata pelajaran IPS Terpadu untuk lebih memperhatikan siswa dalam proses pembelajaran.

2. Bagi orang tua

Hasil penelitian ini diharapkan dapat menyentuh hati orang tua anak atu wali murid untuk lebih memperhatikan jadwal belajar anak dan mengawasi kegiatan anak dirumah agar anak mempunyai pengetahuan yanglebihluasdariapa yang diharapkan.

3. Bagi siswa

ini diharapkan dapat meningkatkan belajar siswa, Hasil penelitian untuk mengasah kemampuan yang baik dirumah maupun disekolah dimilikian agar dapat di tuangkan dalam kegiatan pembelajaran untuk memperoleh prestasi yang meningkat. 
4. Bagi peneliti

Agar peneliti dapat melihat bagaimana menjadi guru yang baik didalam proses pembelajaran dan menjadi khasanah ilmu yang bermanfaat buat peneliti, peneliti tidak hanya meneliti saja akan tetapi dijadikan pelajaran agar ketika menjadi guru kelak dapat mengambil pelajaran yang bermanfaat dari penelitian ini.

\section{DAFTAR RUJUKAN}

A'la, Miftahul. 2012. Quantum Teaching (Buku Pintar dan Praktis). Yogyakarta: DIVA Press

Aman.2011. Model Evaluasi Pembelajaran Sejarah. Yogyakarta: Penerbit Ombak.

Arifin, A., Ma'ruf, F., \& Yasin, I. (2020). Efektivitas Belajar Al-Qur'an Dengan menggunakan Aplikasi Hijaiyah Berbasis Budaya Lokal "Nggahi Mbojo" (Bahasa Bima) Pada Lansia di Kabupaten Dompu. Ainara Journal (Jurnal Penelitian Dan PKM Bidang Ilmu Pendidikan), 1(1), 24-30. https://doi.org/10.54371/ainj.v1i1.10

Arikunto, Suharsimi.2009. Dasar-Dasar Evaluasi Pendidikian. Jakarta: Bumi Aksara

Arikunto,Suharsimi. 2009. Dasar-Dasar Evaluasi Pendidikan. Jakarta: Bumi Aksara

Baharuddin dan Esa Nur Wahyuni.2010. Teori Belajar dan Pembelajaran.Yogyakarta. Ar-ruzz Media.

CiptaEtin.2012. Untuk PPKN. Jakarta: CV AlfabetaPustaka Bumi AksaraBelajar Solihatin, Statistika Strategi Pembelajaran Penelitian.Bandung:

Depdiknas. 2004. Peningkatan Kualitas Pembelajaran. Jakarta: Depdiknas 2007.Naskah Akademik Kajian Kebijakan Kurikulum Mata Pelajaran IPS .Jakarta: Depdiknas Badan Penelitian dan Pengembangan Pusat Kurikulum.

DePorter, Bobbi, dkk. 2010. Quantum Teaching : Mempraktikan Quantum Learning di Ruang-ruang Kelas. Bandung: Kaifa.

Djamarah, Syaiful Bahri.2010. Guru dan Anak Didik dalam Interaksi Edukatif. Jakarta: Rineka Cipta.

Fathirma'ruf, \& Abubakar Wahyu. (2018). PERANCANGAN STANDAR OPERASIONAL PROSEDUR (SOP) SLIDE PRESENTASI BERBASIS MULTIMEDIA. JIIP - Jurnal Ilmiah Ilmu Pendidikan,1(1), 1-8. Retrieved from http://jiip.stkipyapisdompu.ac.id/jiip/index.php/IIIP/article/view/cob.pdf

Fathirma'ruf, \& Muhammad Akbar. (2018). Perancangan Sistem Seleksi Penerimaan Calon Mahasiswa Baru Berbasis Website. JIIP - Jurnal Ilmiah Ilmu Pendidikan,1(3), 102-106. Retrieved from http://jiip.stkipyapisdompu.ac.id/jiip/index.php/IIIP/article/view/28

Hamalik, Oemar. 1995. Kurikulum dan Pembelajaran. Jakarta : Bumi Aksara.

http://www.kemdiknas.go.id/kemdikbud/tentang-kemdikbudvisi (diakses tanggal 1 Januari 2013)

Imansyah, M. Nur, and Asmedy Asmedy. "Akselerasi covid-19 pada proses pembelajaran di era pendidikan 4.0." JPPI (Jurnal Penelitian Pendidikan Indonesia) 7.2 (2021): 279-284.

Kartodirjo, Sartono. 1992. Pendidikan Ilmu Sosial dalam Metodologiejarah. Jakarta: Gramedia Pustaka Utama.

Kemendiknas.(2012). Visi dan Misi Kementerian Pendidikan dan di Kebudayaan. Tersedia

Kochhar. S. K. 2008. Pembelajaran Sejarah, Teaching of History. Jakarta. PT Gramedia.

Kuntowijoyo. 1995. Pengantar Ilmu Sejarah. Yogyakarta: Yayasan Bentang Budaya. 
Lapono, Nabisi. 2008. Belajar dan Perkembangan. Pembelajaran Semarang: SD. Jakarta: Unnes Depdiknas.Press

Ma'ruf, F. (2021). Pengembangan Game Edukasi Berbasis Flash Sebagai Sarana Belajar Siswa PAUD. Ainara Journal Uurnal Penelitian Dan PKM Bidang Ilmu Pendidikan), 2(3), 143-147. https://doi.org/10.54371/ainj.v2i3.68

Margono, S. 2005. Metodologienelitian Pendidikan. Jakarta: P.T Rineka Cipta.

Mulyasa, E. 2008.Implementasi Kurukulum Tingkat Satuan Pendidikan, Kemandirian Guru Dan Kepala Sekolah. Jakarta: Bumi Aksara.

Rifa'i, Achmat.2009.Psikologi yang Mempengaruhi. Jakarta : Rineka Slameto. 2010. Belajar dan FaktorFaktor

Sanjaya, Wina. 2006. Strategi Pembelajaran Berorientasi Standar Proses Pendidikan.Jakarta: Prenada Media.

Sardiman. 2001. Interaksi danMotivasi Belajar Mengajar. Jakarta: PT. Rajagrafindo Persada.

Sudjana, Nana. 2005. Metode Statistika. Bandung: Tarsito.--. 2009. Penilaian Hasil Proses Belajar Mengajar. Bandung: PT Remaja Rosdakarya.

Sugiyanto. 2010. Model-model Pembelajaran Inovatif. Surakarta: Yuma Pustaka.

Sugiyono. 2009. Metode Penelitian Kuantitatif, kualitatif, dan R \& D. Bandung: Alfabeta.

Sugiyono.2006. Suprijono, Suryosubroto. Agus.2011. 2009. Proses Cooperatif Belajar Learning. Mengajar Yogyakarta: di Sekolah. Jakarta: Rineka Cipta

Wena, Made. 2011. Strategi Pembelajaran Inovatif Kontemporer Suatu Tinjauan Konseptual Operasional. Jakarta: Bumi Aksar http://muhsinhar.staff.umy.ac.id/memahami-peta-konsepatau-mind-map/ diakses tanggal 16 Agustus 2013. 